\title{
Approach to psychotherapy in generalized anxiety disorder in the primary health care
}

\author{
Khalid Kulaib Aloufi ${ }^{1 *}$, Fatima Mohammad Kaki ${ }^{1}$, Abbas Hassan Al Lashit ${ }^{2}$, \\ Nawaf Hussein Al Habshi ${ }^{3}$, Hussain Fuad Alsaffar ${ }^{4}$, Aseel Abubakr Hamza ${ }^{5}$, \\ Mohammed Abdulrahman Alaqlan ${ }^{6}$, Walaa Abdullah Takrooni ${ }^{7}$, Ruba Mohammad Mandora ${ }^{7}$, \\ Nabeel Ali Althabi ${ }^{6}$, Meshari Khaled Alzekrey ${ }^{8}$, Hatan Adnan Khan ${ }^{9}$, Hattan Siddiq Saeedi ${ }^{10}$
}

\author{
${ }^{1}$ Department of Psychiatry, Al-Amal Mental Health and Addiction Treatment Hospital, Jeddah, Saudi Arabia \\ ${ }^{2}$ Primary Health Care, Qatif central hospital, Qatif, Saudi Arabia \\ ${ }^{3}$ Department of Family Medicine, King Saud Medical City, Riyadh, Saudi Arabia \\ ${ }^{4}$ College of Medicine, Imam Abdulrahman Bin Faisal University, Dammam, Saudi Arabia \\ ${ }^{5}$ College of Medicine, King Abdulaziz University, Jeddah, Saudi Arabia \\ ${ }^{6}$ College of Medicine, Wroclaw Medical University, Wroclaw, Poland \\ ${ }^{7}$ College of Medicine, Umm Al-Qura University, Saudi Arabia \\ ${ }^{8}$ College of Medicine, King Saud bin Abdulaziz University for Health Sciences, Riyadh, Saudi Arabia \\ ${ }^{9}$ Transformation Management, King Fahad General Hospital, Jeddah, Saudi Arabia \\ ${ }^{10}$ Department of Emergency Medicine, Hera General Hospital, Mecca, Saudi Arabia
}

Received: 28 December 2020

Accepted: 13 January 2021

\section{*Correspondence:}

Dr. Khalid Kulaib Aloufi,

E-mail: oufi-psych@hotmail.com

Copyright: (c) the author(s), publisher and licensee Medip Academy. This is an open-access article distributed under the terms of the Creative Commons Attribution Non-Commercial License, which permits unrestricted non-commercial use, distribution, and reproduction in any medium, provided the original work is properly cited.

\begin{abstract}
Although medications have shown great efficacies in managing generalized anxiety disorder (GAD), recent evidence shows that patients tend to psychotherapy as their first-line of management due to the frequency of side effects resulting from the prolonged use of these medications. Psychotherapy is defined as the using certain and defined psychological modalities for the management of an emotional or mental illness on the condition that the aim and deadline of the therapy have been pre-determined. In this review, we present a brief about the psychological management of patients with GAD. We have identified three psychological modalities for the management of GAD as previous studies have compared them to the usual care by pharmacological modalities or a placebo. These include cognitive-behavioral (CBT), interpersonal, and supportive therapies. We found that management of GAD using CBT, interpersonal or supportive therapies is significantly efficacious in reducing GAD symptoms and increase the possibilities of recovery in addition to reducing the recovery or relapse rates. By doing this, we expect that the managed patient's quality of life would be improved. We also recommend that the management approach should be case-sensitive for each patient depending on the patient's status, the severity of the disease, and the responsiveness of the patient.
\end{abstract}

Keywords: Generalized anxiety disorder, CBT, Psychotherapy, Interpersonal, Supportive

\section{INTRODUCTION}

Generalized anxiety disorder (GAD) is marked as the commonest anxiety disorder in the older population with an estimated prevalence rate of $2.4-6.3 \% .^{1,2}$ Previous research even suggests the rate is higher than the estimated numbers which are probably because disabilities are significantly associated with a milder form 
of the condition named subthreshold GAD. ${ }^{3}$ It is a chronic and activity-limiting condition for all patients of different age groups. It is also associated with symptoms as cognitive impairment and increased disabilities which may impact the affected patients' quality of life and increase their chances for requiring medical care. ${ }^{4-8}$ Parmelee et al also reported that co-morbidities may occur which can complicate the case, as noticed with patients of depression with an estimated prevalence rate of $60 \% .^{9}$ Many variations have been found within the brain networks of the patients affected with GAD which may explain how these patients create and respond to the different episodes of the disease. ${ }^{10}$

At first, GAD was classified in the DSM-III and was first described by Freud back in 1920 as being an anxiety of neurosis. ${ }^{11} \mathrm{He}$ differentiated between the directed or specific feelings of worry that could be seen in the phobic neurosis and the somatic and non-specific one that is associated with and attributable to anxiety neurosis. ${ }^{11,12}$ According to Borkovec et al, this discrimination is essential in differentiating between the different types of GAD and from similar disorders making it a distinct DSM-III disease. ${ }^{13}$ Many medications are involved in the management of GAD. These include selective serotonin reuptake inhibitors, anxiolytics, serotonin-norepinephrine reuptake inhibitors, and tricyclic antidepressants. ${ }^{14}$ Antidepressant drugs are considered the first-line of management of this disorder as they can be used to manage worry and depression which are commonly associated with GAD. In the past, benzodiazepines were also applied on a wide level as they were used to treat anxiety and are also sedative. However, new guidelines suggest that these compounds should not be used for a long period with a maximum period of 4 weeks to prevent the occurrence of tolerance which may commonly occur with these compounds. ${ }^{14}$

Although medications have shown great efficacies in managing GAD, recent evidence shows that patients tend to psychotherapy as their first-line of management due to the frequency of side effects resulting from the prolonged use of these medications. ${ }^{15}$ Psychotherapy is defined as the using certain and defined psychological modalities for the management of an emotional or mental illness on the condition that the aim and deadline of the therapy have been pre-determined. In this review, we present a brief about the psychological management of patients with GAD.

\section{METHODS}

We performed an extensive literature search of the Medline, Cochrane, and EMBASE databases on $20^{\text {th }}$ December 2020 using the medical subject headings (MeSH) or a combination of all possible related terms. Studies discussing the psychological management of patients with GAD were screened for relevant information. We did not pose any limits on date, language, or publication type.

\section{DISCUSSION}

At first, it must be noted that the treatment of GAD is different from other anxiety forms that is because GAD patients are worried about different types of stimuli including real and imaginary ones, on the other hand, other anxiety patients present with feelings from an existing stimulus.

\section{Cognitive-behavioral therapy (CBT)}

Evidence shows that CBT is the most commonly used modality for the management of GAD as a treatment of choice, however, it is worth noting that CBT should be adjusted for the different GAD models. For the management of GAD using CBT, the management process should be applied to seven steps and components. These include (1) patient's self-monitoring of potential sources of harmful feelings, thoughts, behaviors, and situations, (2) application of relaxative approaches like diaphragmatic breathing and conscious muscle relaxation in addition to performing peaceful activities, (3) encouragement of self-confidence and control, (4) trying to avoid and control harmful stimuli, (5) reconstruction of the patient's cognition and trying to found more enhanced approaches to increase his flexible thoughts, (6) promoting the feelings of present-moment living, and (7) asking the patient to leave expectations. ${ }^{16}$ The same focuses were also used by Borkovec's avoidance theory of worry in combination with another focus directing the patient to identify and the possible worrying emotions. A previous randomized controlled trial by Newman et al assessed the CBT focuses augmentation with this focus on 83 participants. ${ }^{17}$ The authors concluded that no significant difference was found between the two groups of the study indicating that CBT augmentation with emotional processing is not always productive and other modalities should be approached. There are two main goals for the application of psychotherapy on the metacognitive model of GAD. The first one is the alteration of the patient's concerns and behavior towards worry and annoying feelings and is done by the psychotherapist. The second one is that the patient introduces other alternatives to deal with these feelings and help him encounter them. Davey et al demonstrated in their book that such treatment strategies must involve the integration of the following elements: socialization, case formulation, and making positive discussions with the patient about the hazards of uncontrollability and fear. ${ }^{18}$ During such sessions, the patient is asked to identify the feelings that make him worried, and how he reacts to them, in addition to his attempts to contain such attacks or episodes. Consequently, this can lead to the identification of the patient's GAD attacks triggers and will give the physician a good picture of how the patients react to such situations including the positive and negative points. The aim of socialization is make the patients less worried and is open to share his experience with the doctor in addition to making the patient aware of the aim of the therapy to 
achieve a better outcome. Mismatch strategy can also be used following this to relieve anxiety.

According to emotion dysregulation approaches, psychotherapy is considered to integrate the following: (1) the aforementioned elements and focuses of the CBT, (2) dialectic, and acceptance-based management of behavior, and (3) experiment-based management to teach the patient how to control and avoid the bad feelings. ${ }^{19}$ These emotional regulation approaches have been continuously updated and evidence shows that they are composed of four phases. The first phase is approaching the patient and teaching him about the role of emotions and how they can be harmful and the importance of controlling them. It also includes raising the patient's awareness about his health of mentality and somatic stabilities. In the second phase, the patient is taught how to deal with anxiety triggers to accept such emotions through some skills that should be taught by the physician. The second phase is experimental where the patient is told that he will be exposed to the anxiety triggers that he complained about and the doctor should notice how he will act accordingly based on the previously taught skills. Skill consolidation should be finally taught in the last phase where the final evaluation of the patient should be conducted before he is released. Besides, in this phase, the doctor should educate the patient about how to react in severe situations to prevent relapses.

For assessment of CBT, many recent RCTs have been published for this purpose. Stanely et al conducted an RCT of adults in a primary care setting to compare the effect of applying CBT as an intervention versus the application of the usual care for the control group. ${ }^{20}$ The authors reported that they could estimate a significant improvement in depression, worry, and general mental health in the group where CBT was applied. In the same context, a previous meta-analysis of 985 RCTs was also conducted to estimate the efficacy of CBT in the management of GAD. As usual, the authors reported that this modality was significantly better in managing these patients when compared to other modalities that were applied to the control groups as pharmacological therapy, for instance. ${ }^{21}$ The advantage of CBT is that it is easy to deliver and is suitable for the disease, the management of which requires making the patient at the comfort they need to face other triggers, unlike other approaches which may lack the possibility of compliance. From this point of view, Brenes et al conducted an RCT to assess the efficacy of telephone CBT for a rural old population with GAD. ${ }^{22}$ The authors depended that by conducting this modality, patients will receive at least 9 secessions to provide a healthy atmosphere for them and help them get through an attack. The authors reported that after four months of follow-up, they could notice, by an over the phone assessment interview, that conducting such an approach was significantly associated with the reduction of GAD symptoms as depression and worry, according to the included patients. This was also supported by previous studies in the literature which have assessed the long-term effect of telephone CBT on GAD symptoms and management. . $^{23,24}$

\section{Interpersonal and supportive therapy}

Previous systematic reviews have reviewed the efficacy of interpersonal therapy compared to pharmacological medications in many terms. A meta-analysis of four RCTs was conducted by Jakobsen et al and showed that interpersonal therapy was significantly able to reduce the sense of depression among the included patients in addition to reducing the frequency of remission among them. ${ }^{25}$ However, the authors reported that all of the included trials were estimated to have a risk of bias which may affect the quality of reporting. Another meta-analysis by Linde et al also aimed to assess the efficacy of interpersonal therapy in treating GAD comparing it to a placebo group or a group where usual care was offered, according to the included $\mathrm{RCT} .{ }^{26}$ The results were also similar to the previous meta-analysis as authors concluded that interpersonal therapy was more efficacious than other groups. In the same context, Biescheuvel-Leliefeld et al conducted a systematic review to compare the efficacy of interpersonal therapy versus antidepressants in terms of reducing relapses of GAD. ${ }^{27}$ The authors reported that interpersonal therapy was also significantly more effective than these medications on this occasion. Another meta-analysis of three studies was also conducted for the same purpose in patients with a complete recovery from GAD to assess the efficacy of the interpersonal history in preventing the relapses. The authors reported that interpersonal history was significantly useful in decreasing the possibility of GAD recurrence when compared to the control groups which received usual care or a pharmacological medication at 12 months from the beginning of the study. However, the author reported that this significance was lost at 24 months of follow-up. Therefore, it is essential to continue interpersonal history every year to eliminate the risk of recurrence. ${ }^{28}$ We have also identified previous studies that compared the efficacy of supportive therapy in the management of GAD with other usual modalities. In a systematic review conducted by Cuijpers et al. ${ }^{29}$ on 22 studies to assess the efficacy of psychotherapy in the management of GAD when compared to other modalities. The authors reported that significant improvements were noticed in patients that were indicated for supportive therapy over patients that received the usual care or a placebo. On the other hand, no significant improvements were noticed between using supportive therapy or pharmacological care. Another meta-analysis was also conducted by Churchil et al and proved that supprotive therapy significantly improved the recovery of the patients that were indicated for it more than other patients that received the pharmacological therapy. ${ }^{30}$ It is worth mentioning that this review included three studies from the previous review by Cuijpers et al and added a new one only to their analysis which opens the way for 
attrition bias. ${ }^{29}$ Therefore, further investigations with big samples are needed.

\section{CONCLUSION}

In our perspective and according to the results obtained from the relevant studies in the literature, we recommend that psychotherapeutic approaches should be preferred to other modalities including pharmacological ones. We found that management of GAD using CBT, interpersonal or supportive therapies is significantly efficacious in reducing GAD symptoms and increase the possibilities of recovery in addition to reducing the recovery or relapse rates. By doing this, we expect that the managed patient's quality of life would be improved. We also recommend that the management approach should be case-sensitive for each patient depending on the patient's status, the severity of the disease, and the responsiveness of the patient.

Funding: No funding sources

Conflict of interest: None declared

Ethical approval: Not required

\section{REFERENCES}

1. Wittchen HU, Jacobi F, Rehm J, Gustavsson A, Svensson M, Jönsson B et al. The size and burden of mental disorders and other disorders of the brain in Europe 2010. European neuropsychopharmacology. J Eur College Neuropsychopharmacol. 2011;21(9):655-79.

2. Golden J, Conroy RM, Bruce I, Denihan A, Greene $\mathrm{E}$, Kirby $\mathrm{M}$ et al. The spectrum of worry in the community-dwelling elderly. Aging mental health. 2011;15(8):985-94.

3. Miloyan B, Byrne GJ, Pachana NA. Threshold and subthreshold generalized anxiety disorder in later life. The American journal of geriatric psychiatry. J Am Asso Geriat Psychiatry. 2015;23(6):633-41.

4. Revicki DA, Travers K, Wyrwich KW, Svedsater H, Locklear J, Mattera MS et al. Humanistic and economic burden of generalized anxiety disorder in North America and Europe. J affective disorders. 2012;140(2):103-12.

5. Brenes GA, Guralnik JM, Williamson JD, Fried LP, Simpson C, Simonsick EM et al. The influence of anxiety on the progression of disability. J Am Geriatr Soc. 2005;53(1):34-9.

6. Porensky EK, Dew MA, Karp JF, Skidmore E, Rollman BL, Shear MK et al. The burden of late-life generalized anxiety disorder: effects on disability, health-related quality of life, and healthcare utilization. Am j geriatr psychiatry. 2009;17(6):47382.

7. Beaudreau SA, O'Hara R. Late-life anxiety and cognitive impairment: a review. Am J geriatr psychiatry. 2008;16(10):790-803.

8. Stanley MA, Diefenbach GJ, Hopko DR. The Nature of Generalized Anxiety in Older Primary Care
Patients: Preliminary Findings. J Psychopathol Behavioral Assessment. 2003;25(4):273-80.

9. Parmelee PA, Katz IR, Lawton MP. Anxiety and Its Association With Depression Among Institutionalized Elderly. Am J geriatric psychiatry. 1993;1(1):46-58.

10. Andreescu C, Sheu LK, Tudorascu D, Gross JJ, Walker S, Banihashemi L et al. Emotion reactivity and regulation in late-life generalized anxiety disorder: functional connectivity at baseline and posttreatment. Am J geriatr psychiatry. 2015;23(2):20014.

11. Garfinkle EJ, Behar E. Advances in Psychotherapy for Generalized Anxiety Disorder. Curr Psychiatry Rep. 2012;14(3):203-10.

12. Heimberg RG, Turk CL, Mennin DS. Generalized anxiety disorder: Advances in research and practice. Guilford Press. 2004.

13. Borkovec T, Alcaine O, Behar E, Heimberg R, Turk C, Mennin D. Generalized anxiety disorder: Advances in research and practice. New York: Guilford. 2004:77-108.

14. Association CP. Clinical practice guidelines. Management of anxiety disorders. Can J psychiatry Revue canadienne de psychiatrie. 2006;51(8 Suppl 2):9S.

15. Hunot V, Churchill R, Silva de Lima M, Teixeira V. Psychological therapies for generalised anxiety disorder. Cochrane Database Syst Rev. 2007;2007(1):Cd001848.

16. Borkovec TD, Newman MG, Pincus AL, Lytle R. A component analysis of cognitive-behavioral therapy for generalized anxiety disorder and the role of interpersonal problems. J consulting clin psychol. 2002;70(2):288.

17. Newman MG, Castonguay LG, Borkovec TD, Fisher AJ, Boswell JF, Szkodny LE et al. A randomized controlled trial of cognitive-behavioral therapy for generalized anxiety disorder with integrated techniques from emotion-focused and interpersonal therapies. J consulting clin psychol. 2011;79(2):17181.

18. Davey GC, Wells A. Worry and its psychological disorders: Theory, assessment and treatment. John Wiley and Sons. 2006.

19. Kring AM, Sloan DM. Emotion regulation and psychopathology: A transdiagnostic approach to etiology and treatment. Guilford Press. 2009.

20. Stanley MA, Wilson NL, Novy DM. Cognitive behavior therapy for generalized anxiety disorder among older adults in primary care: a randomized clinical trial. Jama. 2009;301(14):1460-7.

21. Hall J, Kellett S, Berrios R, Bains MK, Scott S. Efficacy of Cognitive Behavioral Therapy for Generalized Anxiety Disorder in Older Adults: Systematic Review, Meta-Analysis, and MetaRegression. Am J geriatr psychiatry. 2016;24(11):1063-73.

22. Brenes GA, Danhauer SC, Lyles MF, Hogan PE, Miller ME. Telephone-Delivered Cognitive 
Behavioral Therapy and Telephone-Delivered Nondirective Supportive Therapy for Rural Older Adults With Generalized Anxiety Disorder: A Randomized Clinical Trial. JAMA psychiatry. 2015;72(10):1012-20.

23. Brenes GA, Danhauer SC, Lyles MF, Anderson A, Miller ME. Long-Term Effects of TelephoneDelivered Psychotherapy for Late-Life GAD. Am J geriatr psychiatry. 2017;25(11):1249-57.

24. Brenes GA, Danhauer SC, Lyles MF, Miller ME. Telephone-delivered psychotherapy for ruraldwelling older adults with generalized anxiety disorder: study protocol of a randomized controlled trial. BMC psychiatry. 2014;14:34.

25. Jakobsen JC, Hansen JL, Simonsen E, Gluud C. The effect of interpersonal psychotherapy and other psychodynamic therapies versus 'treatment as usual' in patients with major depressive disorder. PLoS One. 2011;6(4):e19044.

26. Linde K, Sigterman K, Kriston L, Rücker G, Jamil S, Meissner $\mathrm{K}$ et al. Effectiveness of psychological treatments for depressive disorders in primary care: systematic review and meta-analysis. Ann family med. 2015;13(1):56-68.

27. Biesheuvel-Leliefeld KE, Kok GD, Bockting CL. Effectiveness of psychological interventions in preventing recurrence of depressive disorder: metaanalysis and meta-regression. $\mathrm{J}$ affective disorders. 2015;174:400-410.

28. Clarke K, Mayo-Wilson E, Kenny J, Pilling S. Can non-pharmacological interventions prevent relapse in adults who have recovered from depression? A systematic review and meta-analysis of randomised controlled trials. Clin psychol review. 2015;39:58-70.

29. Cuijpers P, Driessen E, Hollon SD, Van Oppen P, Barth J, Andersson G. The efficacy of non-directive supportive therapy for adult depression: a metaanalysis. Clin psychol review. 2012;32(4):280-91.

30. Churchill R, Hunot V, Corney R, Knapp M, McGuire $\mathrm{H}$, Tylee A et al. A systematic review of controlled trials of the effectiveness and cost-effectiveness of brief psychological treatments for depression. Health technol assessment (Winchester, England). 2001;5(35):1-173

Cite this article as: Aloufi KK, Kaki FM, Alashit AH, Al Habshi NH, Alsaffar HF, Hamza AA, et al. Approach to psychotherapy in generalized anxiety disorder in the primary health care. Int J Community Med Public Health 2021;8:954-8. 